\title{
Preparation of Hexagonal Plate-like ZnO Single- crystal Particles in the Presence of Anionic Amphiphiles
}

\author{
Hirobumi Shibata ${ }^{1,2 *}$, Yoshinobu lizuka', Takayuki Kawai ${ }^{1}$, Yoshito Watai ${ }^{1}$, \\ Masato Amano ${ }^{1}$, Atsuhiro Fujimori ${ }^{3}$, Taku Ogura ${ }^{2,4}$, and Kazuaki Hashimoto ${ }^{1}$ \\ ${ }^{1}$ Faculty of Engineering, Chiba Institute of Technology, 2-17-1 Tsudanuma, Narashino, Chiba 275-0016, JAPAN \\ ${ }^{2}$ Research Institute for Science and Technology, Tokyo University of Science, 1-3 Kagurazaka, Shinjuku-ku, Tokyo 162-8601, JAPAN \\ ${ }^{3}$ Graduate School of Science and Engineering, Saitama University, 255 Shimo-okubo, Sakura-ku, Saitama 338-8570, JAPAN \\ ${ }^{4}$ NIKKOL GROUP Cosmos Technical Center, 3-24-3 Hasune, Itabashi -ku, Tokyo 174-0046, JAPAN
}

\begin{abstract}
In this study, we synthesized $\mathrm{ZnO}$ particles using anionic amphiphiles as an additive. While the single-crystal particles prepared in the absence of such amphiphiles had a hexagonal rod-like shape, those fabricated using anionic amphiphilic molecules had a hexagonal plate-like shape. The anionic amphiphiles inhibited crystal growth in the $c$-axis direction of $\mathrm{ZnO}$. This demonstrated that the anionic surfactants served as crystal-growth-directing agents, controlling the shape of the $\mathrm{ZnO}$ particles.
\end{abstract}

Key words: zinc oxide, single crystal, anionic amphiphiles, crystal-growth-directing agents

Zinc oxide $(\mathrm{ZnO})$ is one of the most important materials used in photocatalysts ${ }^{1-9)}$ and electronic devices ${ }^{10-20)}$. The particle size, particle shape, and crystallinity strongly affect the physical and chemical properties of ZnO. By varying reaction conditions such as the species used as the zinc oxide precursor, the $\mathrm{pH}$ value, the reaction temperature, the reaction time, and the additives used, the particle size, particle shape, crystallinity, and orientation can be easily controlled $^{21}$. The present investigation aimed to achieve control of the shape and properties of $\mathrm{ZnO}$ by changing the reaction conditions. Various $\mathrm{ZnO}$ shapes, such as rods, tetrapods $^{22-24)}$ and flower-like particles ${ }^{25-28)}$, were clearly identified. These structures were assumed to be the polar surfaces of $c$-faces. Here, two-dimensional materials, such as sheet-like structure, have gathered increasing attention due to their possible applications to heterogeneous catalysts and energy-related materials ${ }^{29-31)}$. However, two-dimensional $\mathrm{ZnO}$ has not been reported.

Amphiphilic molecules often form self-assemblies and are adsorbed on inorganic materials in specific ways. These properties have been exploited in the synthesis of inorganic materials. Much effort has been devoted to the fabrication of mesoporous inorganic materials using self-assemblies of amphiphiles as templates ${ }^{32-39)}$. Mesoporous materials are typically synthesized using cationic surfactants as amphiphilic molecules. On the other hand, specific adsorption of amphiphiles often occurs on inorganic materials ${ }^{40-42}$. This property promises that the synthesis of $\mathrm{ZnO}$ particles with amphiphiles as additives will provide a novel technique for controlling the particle shape, particle size, crystallinity, and orientation of $\mathrm{ZnO}$ due to their specific adsorption. However, few studies have addressed the synthesis of $\mathrm{ZnO}$ using amphiphilic molecules as additives. Here, we report a novel technique for preparing $\mathrm{ZnO}$ single-crystal particles using anionic amphiphiles. We also demonstrate the role of anionic amphiphilic molecules in the formation of $\mathrm{ZnO}$.

Zinc sulfate heptahydrate $\left(\mathrm{ZnSO}_{4} \cdot 7 \mathrm{H}_{2} \mathrm{O}\right.$; Wako Pure Chemical Industries, Ltd.) and sodium hexadecyl sulfate (SHS; Wako Pure Chemical Industries, Ltd.) were used as the zinc oxide precursor and anionic surfactant, respectively. An aqueous ammonia solution(Kanto Chemical Co., Inc.) was used for $\mathrm{pH}$ adjustment.

$6.20 \mathrm{~g}$ of SHS was added to $45 \mathrm{ml}$ of ion-exchanged water and stirred at $343 \mathrm{~K}$ for $2 \mathrm{~h}$. The resulting SHS solution, which was adjusted to $\mathrm{pH} 12$ using the ammonia solution, was mixed with $10 \mathrm{ml}$ of $2 \mathrm{M}$ aqueous $\mathrm{ZnSO}_{4}$ solution

*Correspondence to: Hirobumi Shibata, Faculty of Engineering, Chiba Institute of Technology, 2-17-1 Tsudanuma, Narashino, Chiba 275-0016, JAPAN

E-mail: hirobumi.shibata@it-chiba.ac.jp

Accepted April 27, 2020 (received for review March 30, 2020)

Journal of Oleo Science ISSN 1345-8957 print / ISSN 1347-3352 online

http://www.jstage.jst.go.jp/browse/jos/ http://mc.manusriptcentral.com/jjocs 


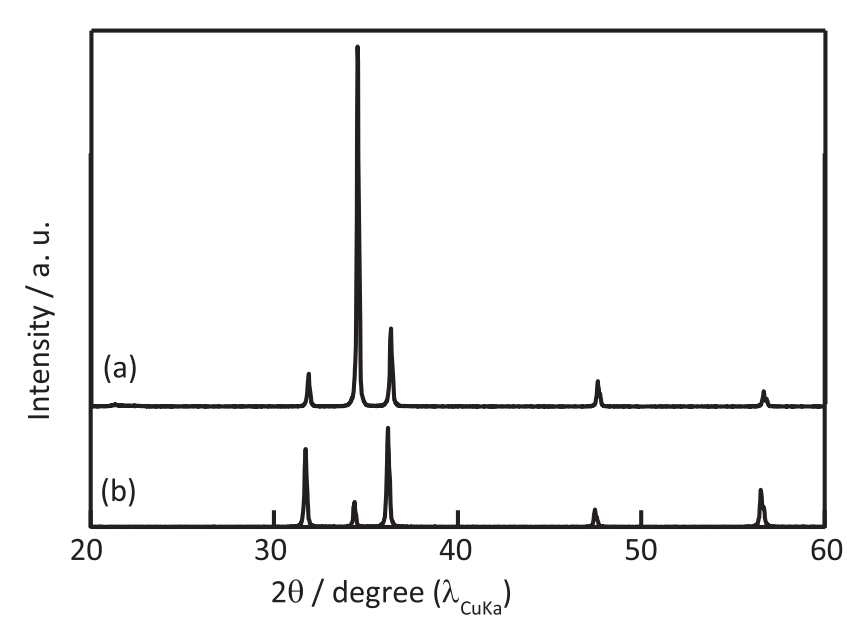

Fig. 1 XRD patterns for particles synthesized in the (a) presence and (b) absence of SHS.

and stirred at $343 \mathrm{~K}$ for $24 \mathrm{~h}$. After stirring, a hydrothermal treatment was carried out at $423 \mathrm{~K}$ for $24 \mathrm{~h}$. For comparison, the particles were synthesized through the same procedure without the addition of SHS. A part of the mixture was centrifuged and washed with ion-exchanged water. The samples obtained were characterized using scanning electron microscopy (SEM; Keyence, VE-7800). The rest of the mixture was filtered, washed with ion-exchanged water and dried at $333 \mathrm{~K}$ for $24 \mathrm{~h}$. The crystal structure of these particles was investigated using X-ray diffraction (XRD; Rigaku, MiniFlex600 CuK $\alpha$ radiation) and high-resolution transmission electron microscopy (TEM; H-9000UHR).

Figure 1 shows XRD patterns of the particles obtained in the (a) presence and (b) absence of SHS. Both XRD patterns showed five diffraction peaks at around 31.8, 34.4, 36.2, 47.5 and $56.6^{\circ}$ due to the (100), (002), (101), (102), and (110) reflections, respectively, indicating the formation of zinc oxide. The intensity of the peak assigned to the (002) reflection of the particles obtained with SHS was higher than that for the particles synthesized without SHS. The intensity ratio $I_{(002)} / I_{(101)}$ was calculated to normalize the intensity of the peak assigned to the (002) reflection with respect to that of the (101) reflection. The $I_{(002)} / I_{(101)}$ ratios for the particles fabricated in the presence and absence of SHS were 4.6 and $2.6 \times 10^{-1}$, respectively. These results suggested that the particles synthesized with SHS were zinc oxide particles with a strong (002) orientation.

Next, we conducted SEM to investigate the morphologies of the synthesized particles. Figure 2 (a) shows an SEM image of hexagonal plate-like particles (size: $10 \mu \mathrm{m}$ ) fabricated in the presence of SHS. The particles fabricated in the absence of SHS had rod-like shapes with a size of around $1.0 \mu \mathrm{m}$ (Fig. 2(b)). Wurtzite (hexagonal crystal system) is known to be the thermodynamically stable crystal structure of $\mathrm{ZnO}$. This means that the $c$-face of $\mathrm{ZnO}$ has a hexagonal structure. The SEM image of ZnO particles synthesized in the presence of SHS strongly suggested that preferential crystal growth of the $c$-face occurred. This is in good agreement with the XRD patterns obtained.

Figure 3 shows electron diffraction (ED) patterns for the samples obtained using a focused ion beam(FIB). Figures 3(a) and 3(b) clearly show ED patterns for the hexagonal face of $\mathrm{ZnO}$ and for a face perpendicular to this hexagonal face. Figures $\mathbf{3}(\mathrm{a})$ and $\mathbf{3}(\mathrm{b})$ indicate that the hexagonal face and perpendicular face are the $c$ and $a$ - $c$ faces, respectively, indicating the formation of $\mathrm{ZnO}$ single-crystal particles. These results clearly showed that the particles obtained in the presence and absence of SHS were hexagonal plate-like and hexagonal rod-like ZnO single-crystal particles, respectively.

Finally, we consider the role of SHS. Figure 4 shows a schematic illustration of the formation mechanism of $\mathrm{ZnO}$ particles in the absence and presence of SHS, respectively. Hexagonal plate-like ZnO single-crystal particles were formed in the presence of SHS. This suggests that SHS was adsorbed on the $c$-faces of $\mathrm{ZnO}$ particles during $\mathrm{ZnO}$ crystal growth and that SHS inhibits crystal growth along the $c$-axis direction. These results indicate that SHS acts as a crystal-growth-directing agent.

In this study, ZnO particles were synthesized in the presence and absence of SHS, and the morphology and crystal structure of the resulting particles were investigated. The particles obtained in the presence and absence of SHS were hexagonal plate-like and hexagonal rod-like single-

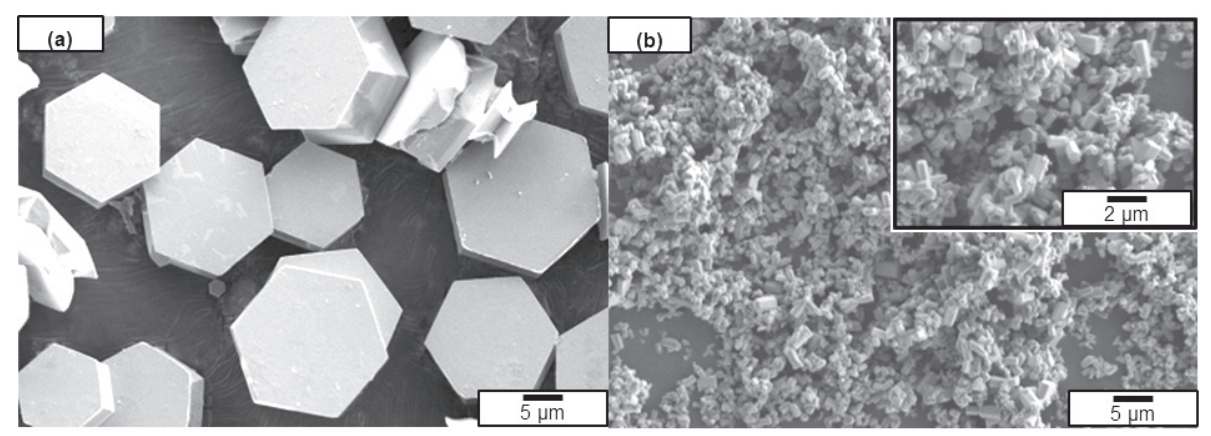

Fig. 2 SEM images of particles synthesized (a) with and (b) without SHS. 


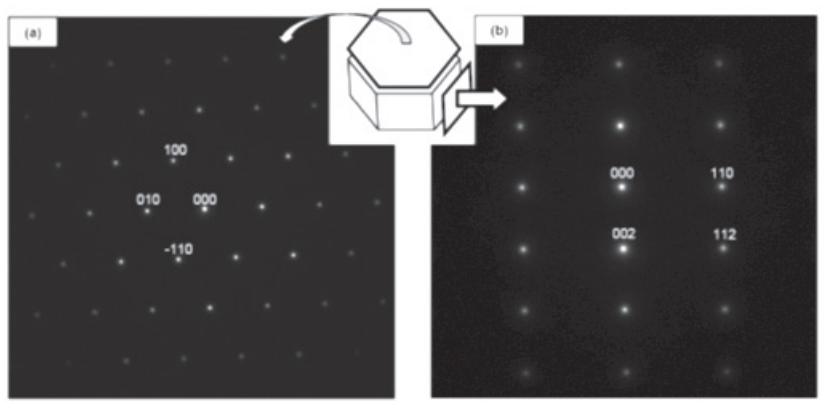

Fig. 3 ED patterns for (a) the hexagonal face and (b) the face perpendicular to the hexagonal face of particles synthesized in the presence of SHS.

crystal ZnO particles, respectively. Clearly, SHS acted as a crystal-growth-directing agent. This represents the first study to use amphiphilic molecules to govern the crystal growth direction. This novel function is expected to play an important role in the fabrication of crystal-growth-controlled inorganic materials.

\section{References}

1) Chen, Y.; Zhao, H.; Liu, B.; Yang, H. Charge separation between wurtzite ZnO polar $\left\{\begin{array}{lll}0 & 0 & 1\end{array}\right\}$ surfaces and their enhanced photocatalytic activity. Appl. Catal. B 163, 189-197(2015).

2) Dong, J.-Y.; Lin, C.-H.; Hsu, Y.-J.; Lu, S.-Y.; Wong, S.-H. Single-crystalline mesoporous $\mathrm{ZnO}$ nanosheets prepared with a green antisolvent method exhibiting excellent photocatalytic efficiencies. Cryst. Eng Comm. 14, 4732-4737 (2012).

3) Zhao, X.; Li, M.; Low, X. Sol-gel assisted hydrothermal synthesis of ZnO microstructures: Morphology control and photocatalytic activity. Adv. Powder Technol. 25, 372-378(2014).
4) Suwanboon, S.; Klubnuan, S.; Jantha, N.; Amornpitoksuk, P..; Bangrak, P. Influence of alkaline solutions on morphology of ZnO prepared by hydrothermal method for using as photocatalyst and bactericidal agent. $M a-$ ter. Lett. 115, 275-278 (2014).

5) Kaneva, N.V.; Dimitrov, D.T.; Dushkin, C.D. Effect of nickel doping on the photocatalytic activity of ZnO thin films under UV and visible light. Appl. Surf. Sci. 257, 8113-8120(2011).

6) Poongodi, G.; Kumar, R.M.; Jayavel, R. Influence of $\mathrm{S}$ doping on structural, optical and visible light photocatalytic activity of ZnO thin films. Ceram. Int. 40, 14733-14740 '(2014).

7) Fouad, O.A.; Ismail, A.A.; Zaki, Z.I.; Mohamed, R.M. Zinc oxide thin films prepared by thermal evaporation deposition and its photocatalytic activity. Appl. Catal. $B$ 62, 144-149 (2006).

8) Gao, G.; Xi, Q.; Zhou, H.; Zhao, Y.; Wu, C.; Wang, L.; Guo, P.; Xu, J. Selectivity of quantum dot sensitized $\mathrm{ZnO}$ nanotube arrays for improved photocatalytic activity. Phys. Chem. Chem. Phys. 19, 11366-11372 (2017).

9) Mukhopadhyay, S.; Maiti, D.; Chatterjee, S.; Devi, P.S.; Kumar, G.S. Design and application of Au decorated $\mathrm{ZnO} / \mathrm{TiO} 2$ as a stable photocatalyst for wide spectral coverage. Phys. Chem. Chem. Phys. 18, 31622-31633 (2016).

10) Daumann, S.; Andrzejewski, D.; Marcantonio, M.D.; Hagemann, U.; Wepfer, S.; Vollkommer, F.; Bacher, G.; Epple, M.; Nannen, E. Water-free synthesis of ZnO quantum dots for application as an electron injection layer in light-emitting electrochemical cells. J. Mater. Chem. C 5, 2344-2351 (2017).

11) Vidor, F.F.; Meyers T.; Hilleringmann, U. Inverter circuits using ZnO nanoparticle based thin-film transistors for flexible electronic applications. Nanomaterials 6, 154/1-154/15(2016).

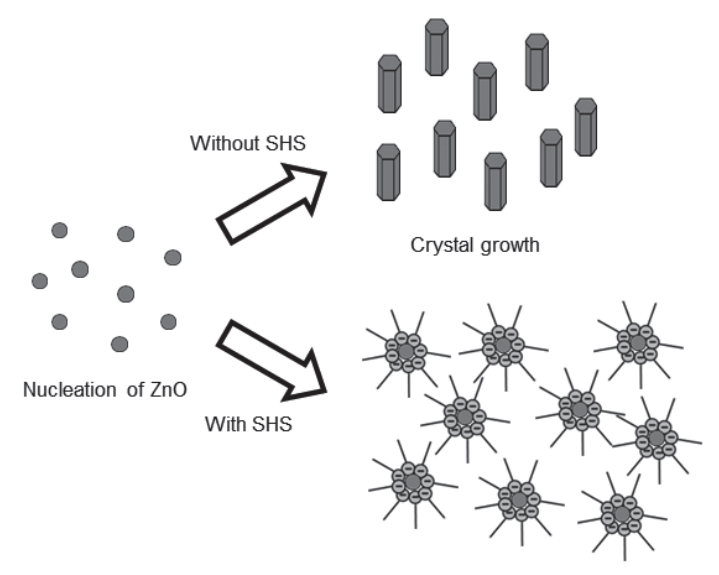

SHS adsorption

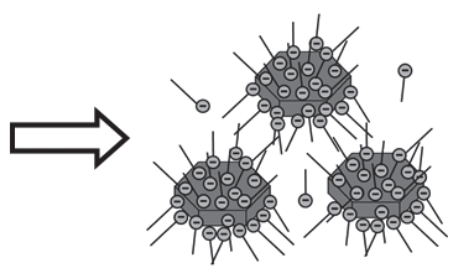

Crystal growth

Fig. 4 Schematic illustration of ZnO particles formation in the absence and presence of SHS, respectively. 
12) Hewlett, R.M.; McLachlan, M.A. Surface Structure Modification of $\mathrm{ZnO}$ and the Impact on Electronic Properties. Adv. Mater. 28, 3893-3921 (2016).

13) Selvi, N.; Sankar, S.; Dinakaran, K. Synthesis, structural and optical characterization of $\mathrm{ZrO}_{2}$ core- $\mathrm{ZnO} @ \mathrm{SiO}_{2}$ shell nanoparticles prepared using co-precipitation method for opto-electronic applications. J. Mater. Sci.: Mater. Electron. 25, 5078-5083(2014).

14) Muguerra, H.; Berthoux, G.; Yahya, W.Z.N.; Kervella, Y.; Ivanova, V.; Bouclé, J.; Demadrille, R. Electrodeposited $\mathrm{ZnO}$ nanowires as photoelectrodes in solid-state organic dye-sensitized solar cells. Phys. Chem. Chem. Phys. 16, 7472-7480 (2014).

15) Pazoki, M.; Nasser, N.; Taghavinia, N. Ab initio study of electronic effects in the $\mathrm{ZnO} / \mathrm{TiO}_{2}$ core/shell interface: application in dye sensitized solar cells. $R S C$ Adv. 4, 301-307(2014).

16) Han, K.N.; Cheng, A.L.; Bui, M.-P.N.; Pham, X.-H.; Seong, G.H. Control of ZnO morphologies on carbon nanotube electrodes and electrocatalytic characteristics toward hydrazine. Chem. Commun. 47, 938-940 (2011).

17) Lee, C.-P.; Lin, J.-C.; Wang, Y.-C.; Chou, C.-Y.; Yeh, M.H.; Vittala, R.; Ho, K.-C. Synthesis of hexagonal ZnO clubs with opposite faces of unequal dimensions for the photoanode of dye-sensitized solar cells. Phys. Chem. Chem. Phys. 13, 20999-21008(2011).

18) Xiang, Y.; Liu, Y.-K.; Chen, Y.-H.; Guo, Y.-B.; Xu, M.-Y.; Ding, Z.; Xia, T.; Wang, J.-H.; Song, Y.-W.; Yang, M.-Z.; Wang, E.; Song, Y.-H.; Yang, S.-L.; She, G.-Q. Investigation of the geometrical effect on photoelectric properties of nano-ZnO with doped liquid crystal technique. Appl. Phys. A 108, 745-750 (2012).

19) Park, S.-H.; Park, J.-W.; Yang, S.-M.; Kim K.-H.; Hwang, N.-M. Effect of Electric Bias on the Deposition Behavior of ZnO Nanostructures in the Chemical Vapor Deposition Process. J. Phys. Chem. C 119, 25047-25052 (2015).

20) Sun, C.; Fu, Y.; Wang, Q.; Xing, L.; Liu, B.; Xue, X. Ultrafast piezo-photocatalytic degradation of organic pollutions by $\mathrm{Ag}_{2} \mathrm{O}$ /tetrapod-ZnO nanostructures under ultrasonic/UV exposure. $R S C A d v$. 6, 87446-87453 (2016).

21) Cho, S.; Jang, J.-W.; Jung, S.-H.; Lee, B.R.; Oh E.; Lee, K.-H. Precursor effects of citric acid and citrates on ZnO crystal formation. Langmuir 25, 3825-3831 (2009).

22) Jian, X.; Chen, X.; Zhou, Z.; Li, G.; Jiang, M.; Xu, X.; Lu, J.; Li, Q.; Wang, Y.; Gou J.; Hui, D. Remarkable improvement in microwave absorption by cloaking a micro-scaled tetrapod hollow with helical carbon nanofibers. Phys. Chem. Chem. Phys. 17, 3024-3031 (2015).

23) Jiang, Y.; Sun, R.; Zhang, H.-B.; Min, P.; Yang, D.; Yu,
Z.-Z. Graphene-coated ZnO tetrapod whiskers for thermally and electrically conductive epoxy composites. Compos. Part A: Appl. Sci. Manuf. 94, 104-112 (2017).

24） Najim, M.; Modi, G.; Mishra, Y.K.; Adelung, R.; Singh, D.; Agarwala, V. Ultra-wide bandwidth with enhanced microwave absorption of electroless Ni-P coated tetrapod-shaped ZnO nano- and microstructures. Phys. Chem. Chem. Phys. 17, 22923-22933(2015).

25) Lin, L.; Liu, H.; Zhang, X. Flower-like ZnO-assisted one-pot encapsulation of noble metal nanoparticles supported catalysts with ZIFs. Appl. Surf. Sci. 433, 602-609 (2018).

26) Zhu, L.; Li, Y.; Zeng, W. Hydrothermal synthesis of hierarchical flower-like $\mathrm{ZnO}$ nanostructure and its enhanced ethanol gas-sensing properties. Appl. Surf. Sci. 427, 281-287 (2018).

27) Lu, Y.; Ma, Y.; Ma, S.; Yan, S. Hierarchical heterostructure of porous $\mathrm{NiO}$ nanosheets on flower-like $\mathrm{ZnO}$ assembled by hexagonal nanorods for high-performance gas sensor. Ceram. Int. 43, 7508-7515(2017).

28) Lam, S.-M.; Quek, J.-A.; Sin, J.-C. Surfactant-free synthesis of $\mathrm{ZnO}$ micro/nanoflowers with efficient photocatalytic antibacterial performance. Mater. Lett. 195, 34-36 (2017).

29) Fiori1, G.; Bonaccorso, F.; Iannaccone1, G.; Palacios, T.; Neumaier, D.; Seabaugh, A.; Banerjee, S.K.; Colombo, L. Electronics based on two-dimensional materials. Nat. Nanotechol. 9, 768-779(2014).

30) Maeda, K.; Mallouk, T.E. Two-dimensional metal oxide nanosheets as building blocks for artificial photosynthetic assemblies. Bull. Chem. Soc. Jpn. 92, 38-54 (2019).

31) He, Y.; Zhuang, X.; Lei, C.; Lei, L.; Hou, Y.; Mai, Y.; Feng, X. Porous carbon nanosheets: Synthetic strategies and electrochemical energy related applications. Nano Today 24, 103-119(2019).

32） Kresge, C.T.; Leonowicz, M.E.; Roth, W.J.; Vartuli, J.C.; Beck, J.S. Ordered mesoporous molecular sieves synthesized by a liquid-crystal template mechanism. $\mathrm{Na}$ ture 359, 710-712 (1992).

33) Attard, G.S.; Glyde, J.C.; Göltner, C.G. Liquid-crystalline phases as templates for the synthesis of mesoporous silica. Nature 378, 366-368 (1995).

34) Davis, S.A.; Burkett, S.L.; Mendelson, N.H.; Mann, S. Bacterial templating of ordered macrostructures in silica and silica-surfactant mesophases. Nature 385, 420-423 (1997).

35） Miyata, H.; Suzuki, T.; Fukuoka, A.; Sawada, T.; Watanabe, M.; Noma, T.; Takada, K.; Mukaide, T.; Kuroda, K. Silica films with a single-crystalline mesoporous structure. Nat. Mater. 3, 651-656 (2004).

36) Shibata, H.; Ogura, T.; Mukai, T.; Ohkubo, T.; Sakai, H.; Abe, M. Direct synthesis of mesoporous titania parti- 
cles having a crystalline wall. J. Am. Chem. Soc. 127, 16396-16397 (2005).

37) Shibata, H.; Mihara, H.; Mukai, T.; Ogura, T.; Kohno, H.; Ohkubo, T.; Sakai, H.; Abe, M. Preparation and formation mechanism of mesoporous titania particles having crystalline wall. Chem. Mater. 18, 2256-2260 (2006).

38) Shibata, H.; Ohkubo, T.; Kohno, H.; Rangsunvigit, P.; Sakai, H.; Abe, M. Preparation and photocatalytic activity of titania particulate film with mesostructured silica as binder. J. Photochem. Photobiol. A 181, 357362 (2006).

39) Shibata, H.; Ohshika, S.; Ogura, T.; Watanabe, S.; Nishio, K.; Sakai, H.; Abe, M.; Hashimoto, K.; Matsumoto, M. Preparation and photocatalytic activity under visible light irradiation of mesostructured titania parti- cles modified with phthalocyanine in the pores. $J$. Photochem. Photobiol. A 217, 136-140(2011).

40) Atkin, R.; Craig, V.S.J.; Wanless, E.J.; Biggs, S. Mechanism of cationic surfactant adsorption at the solidaqueous interface. Adv. Colloid Interface Sci. 103, 219-304 (2003).

41) Suttipong, M.; Grady, B.P.; Striolo, A. Self-assembled surfactants on patterned surfaces: confinement and cooperative effects on aggregate morphology. Phys. Chem. Chem. Phys. 16, 16388-16398(2014).

42) Goloub, T.P.; Koopal, L.K.; Bijsterbosch, B.H.; Sidorova, M.P. Adsorption of cationic surfactants on silica. Surface charge effects. Langmuir 12, 3188-3194 (1996). 